\title{
Paradigms for biologically inspired design
}

\author{
Lenau, T. A.; Metze, A. L. ; Hesselberg, T.
}

Published in:

Proceedings of SPIE

Link to article, DOI:

$10.1117 / 12.2296560$

Publication date:

2018

Document Version

Publisher's PDF, also known as Version of record

Link back to DTU Orbit

Citation (APA):

Lenau, T. A., Metze, A. L., \& Hesselberg, T. (2018). Paradigms for biologically inspired design. In A. Lakhtakia (Ed.), Proceedings of SPIE (Vol. 10593). [1059302] SPIE - International Society for Optical Engineering. https://doi.org/10.1117/12.2296560

\section{General rights}

Copyright and moral rights for the publications made accessible in the public portal are retained by the authors and/or other copyright owners and it is a condition of accessing publications that users recognise and abide by the legal requirements associated with these rights.

- Users may download and print one copy of any publication from the public portal for the purpose of private study or research.

- You may not further distribute the material or use it for any profit-making activity or commercial gain

- You may freely distribute the URL identifying the publication in the public portal

If you believe that this document breaches copyright please contact us providing details, and we will remove access to the work immediately and investigate your claim 


\section{Paradigms for biologically inspired design}

\section{T. A. Lenau, A.-L. Metze, T. Hesselberg}

T. A. Lenau, A.-L. Metze, T. Hesselberg, "Paradigms for biologically inspired design," Proc. SPIE 10593, Bioinspiration, Biomimetics, and Bioreplication VIII, 1059302 (27 March 2018); doi: 10.1117/12.2296560

Event: SPIE Smart Structures and Materials + Nondestructive Evaluation and Health Monitoring, 2018, Denver, Colorado, United States 


\title{
Paradigms for biologically inspired design
}

\author{
T. A. Lenau*a , A.-L. Metze ${ }^{\mathrm{a}}$, and T. Hesselberg ${ }^{\mathrm{b}}$ \\ ${ }^{a}$ Technical University of Denmark (DTU), Dept. of Mechanical Engineering, Produktionstorvet

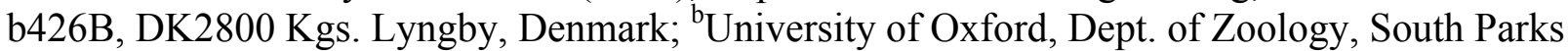 \\ Road, Oxford, OX13PS, United Kingdom
}

\begin{abstract}
Biologically inspired design is attracting increasing interest since it offers access to a huge biological repository of well proven design principles that can be used for developing new and innovative products. Biological phenomena can inspire product innovation in as diverse areas as mechanical engineering, medical engineering, nanotechnology, photonics, environmental protection and agriculture. However, a major obstacle for the wider use of biologically inspired design is the knowledge barrier that exist between the application engineers that have insight into how to design suitable products and the biologists with detailed knowledge and experience in understanding how biological organisms function in their environment. The biologically inspired design process can therefore be approached using different design paradigms depending on the dominant opportunities, challenges and knowledge characteristics. Design paradigms are typically characterized as either problem-driven, solution-driven, sustainability driven, bioreplication or a combination of two or more of them. The design paradigms represent different ways of overcoming the knowledge barrier and the present paper presents a review of their characterization and application.
\end{abstract}

Keywords: Biomimicry, biomimetics, bio-inspired design, problem-driven, solution-driven, bioreplication, nature inspired design.

\section{INTRODUCTION}

Using information and inspiration from living organisms to develop technical artefacts is referred to by a range of different terms like biologically inspired design (BID), biomimetics, biomimicry, bionics and bioreplication. The terms are often used interchangeable but they are not synonyms and although similar they each have their special meaning which can be seen in the international ISO standard ${ }^{1,2}$. The most general term is biologically inspired design (BID) which often is used as a synonym for biomimetics ${ }^{3}$ but also tends to focus more on the design process. Biomimetics is defined in the ISO-standard as the 'interdisciplinary cooperation of biology and technology or other fields of innovation with the goal of solving practical problems through the function analysis of biological systems, their abstraction into models, and the transfer into and application of these models to the solution,1. Biomimicry denotes the "philosophy and interdisciplinary design approaches taking nature as a model to meet the challenges of sustainable development in a social, environmental, and economic perspective'. Bionics constitutes the 'technical discipline that seeks to replicate, increase, or replace biological functions by their electronic and/or mechanical equivalents ${ }^{1}$. Bioreplication is the direct reproduction of a biological structure in order to realize at least one specific functionality ${ }^{4}$. Figure 1 presents a map (inspired by a similar map made by Fayemi ${ }^{5}$ ) of how the different terms relate to one another.

The ISO standard formulate a set of criteria for whether a product can be considered as biomimetic ${ }^{1}$. The criteria relate to the biomimetic design process which was applied to develop the product and include that:

- $\quad$ a function analysis has been made of an available biological system;

- $\quad$ the biological system has been abstracted into a model;

- $\quad$ the model has been transferred and applied to design the product.

*1enau@dtu.dk; phone +45 4525 4811; www.mek.dtu.dk

Bioinspiration, Biomimetics, and Bioreplication VIII, edited by Akhlesh Lakhtakia,

Proc. of SPIE Vol. 10593, 1059302 - (C) 2018 SPIE · CCC code:

0277-786X/18/\$18 - doi: $10.1117 / 12.2296560$ 
All 3 criteria should be satisfied in order for a product to be considered biomimetic. As an example, the ISO-standard describes how reinforced concrete cannot be considered a biomimetic product even though it has similarities to the fibrous structure in plant stems. The reason is that the material structure of the plant stem was not known at the time of the invention of reinforced concrete and an abstraction not made. This reasoning emphasizes the condition that biomimetics require not only similarities between the biological and technical system but also that the core biological principles are identified and isolated and that an abstraction is made into an equivalent technical principle and solution.

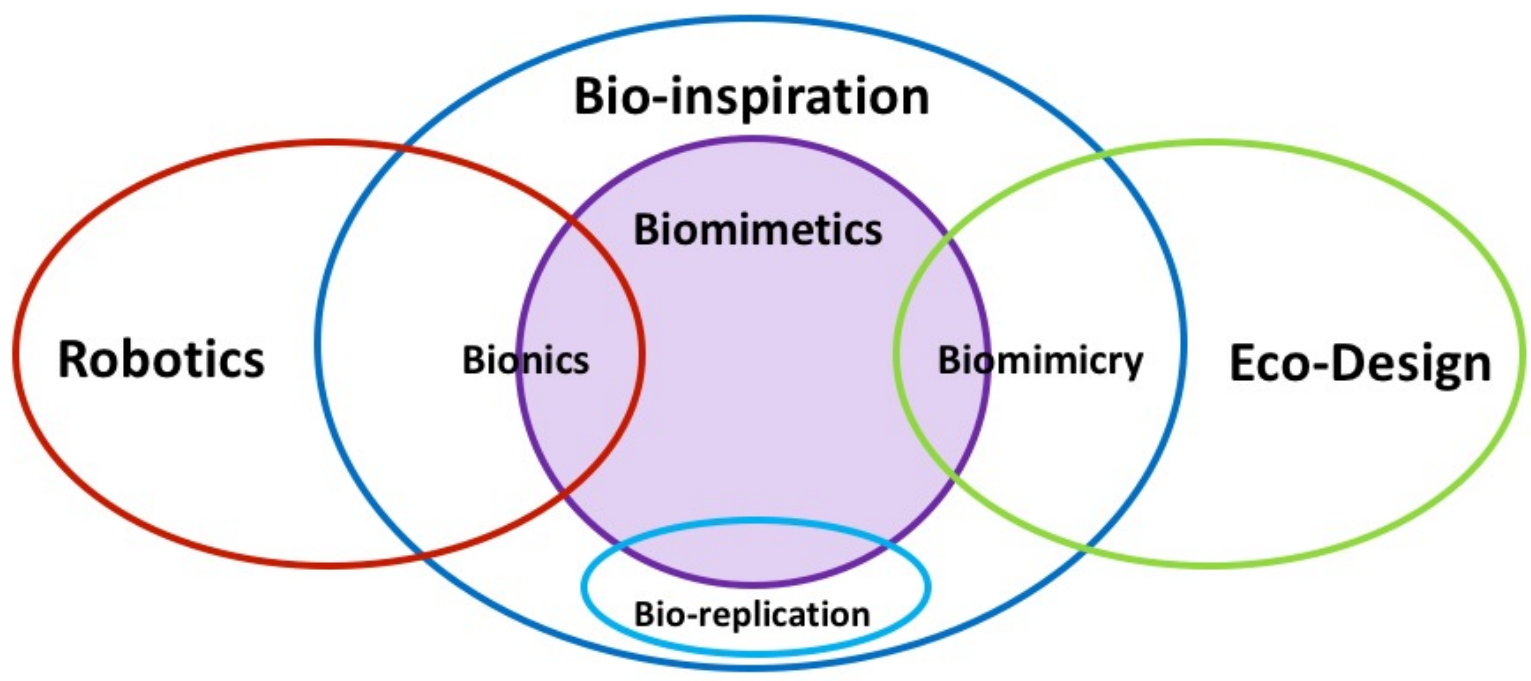

Figure 1. Bio-inspiration and linked concepts boundaries map inspired by a similar map proposed by ${ }^{5}$.

\subsection{Trends in publications and patents}

While we have probably always been inspired by nature in our technological endeavours ranging from using sharp tools to imitate animals' teeth and claws to Leonardo Da Vinci's attempt to develop flying machines based on studies of bat and bird wing morphology, the systematization of this through the scientific disciplines of bionics, biomimetics and biologically inspired design first became established in the second part of the last century ${ }^{6}$. The exponential growth of research into biologically inspired design since then has been documented by a number of studies focusing on either the number of published papers ${ }^{6-8}$ or the number of new patents ${ }^{9,10}$.

In order to see if this trend is continuing we have updated the figures with current data. As can be seen in figure 2, the growth is continuing although there are some indications that it has been slowing down in recent years both in terms of total papers and in terms of the proportion of papers containing the words biomimetics, biomimicry, bionics and biologically inspired design. This could indicate that the growth phase is coming to an end and it will be interesting to see if the proportion of papers will reach an asymptote within the next decade. If so, the proportion of published papers would show a similar sigmoid pattern as that proposed for patents ${ }^{9}$.

Lepora et al. applied an information analysis method to determine the state of the art for biomimetics. They collected a dataset of about 18000 articles describing work on biomimetics and used them to answer four questions ${ }^{8}$. The first question looked upon where biomimetic research is published and they found that more than half the articles were published in 5 journals (Biomaterials, Bioinspiration and Biomimetics, Journal of Biomedical Materials Research A, Langmuir and Acta Biomateriala) while a single conference (ROBIO) had about a third of the papers. For the second question on how rapidly the subject of biomimetics was expanding it was found that the growth rate is increasing with around $6 \%$ per year which equals a doubling in 13 years. The third question on subjects within biomimetics revealed a long range of popular terms with 'robot' and 'control' being the most leading. The fourth question was if there are research communities within biomimetics and by looking at the connectedness of popular terms it was found that five distinct communities with recognisable themes could be identified (robotics and control, ethology-based robotics, biomimetic actuators, biomaterials science and structural bioengineering). 


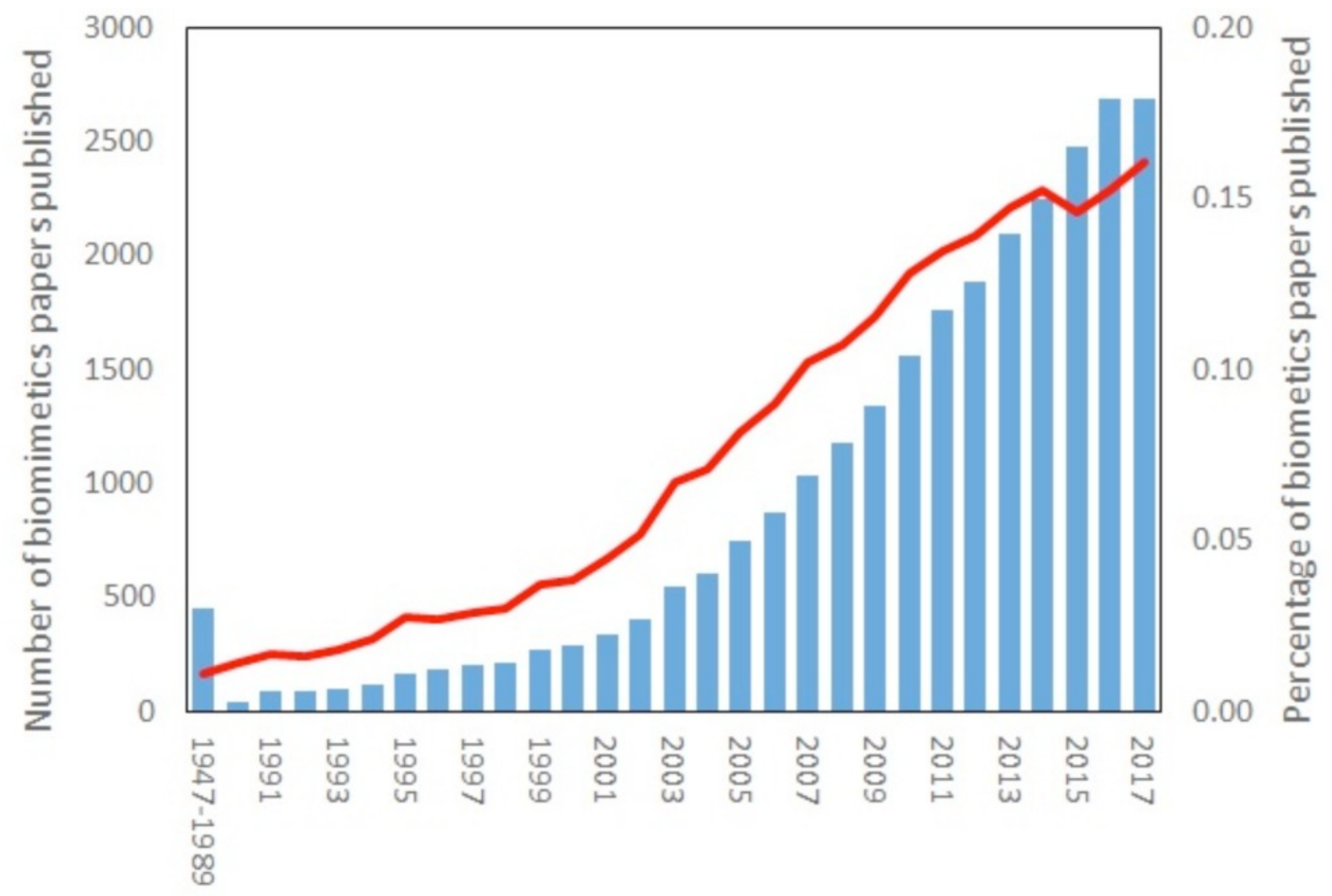

Figure 2. The number of published biomimetics papers in ISI Web of Science. The search was done on articles in the Web of Science core database using the search terms 'biomim*', 'bionic*' and 'biologically inspired' (TS=(biomim* OR bionic* OR biologically inspired)) in the title, keywords or abstract. To get proportional data the number of hits was divided by the total number of published papers (which were assumed to be found searching for 'a' or 'the' in the title, keywords or abstracts - TS=(a OR the*). The bars indicate the number of published biomimetics papers, while the line indicates the proportion of these papers out of the total of all published papers.

To update previously reported trends on the development of patent growth, the same search terms as used by Bonser ${ }^{10}$ were used. The program PatentInspiration ${ }^{11}$ was used with the filter line: biomim* OR bionic* OR "bio* inspired", searching in title, abstract and description and only granted patents, which resulted in a total number of 13,361 patents. The graph in Figure 3 shows a steady rise of patents, with some exceptional years. In 2002 there is a slight decrease, between 2007 and 2010 there are also two years (2008 and 2009) with significantly fewer granted patents, as also seen in 2012 and 2013.

Bonser and Vincent ${ }^{10}$ found a peak of granted US patents (1666) in 2004, while our search only revealed 371 patents worldwide in 2004. This confirms that different database results are difficult to compare due to the individual parameters and search strategies ${ }^{10}$. Doing the same search in the European patent office search engine ${ }^{12}$, in the title and abstract, a total of 6199 patents are found. The equivalent search in PatentInspiration found a total of 5786 patents. These results are closer, but it should be noted that a patent search has a different outcome than a literature search. While in literature, in addition to the title and the abstract, keywords are listed for readers to find papers easier, in patents, it is often the opposite. Even though patents are published for everyone to read, the writer of a patent tries to describe and mask the patent in a way that makes it very difficult to find. Therefore, it can be expected that the number of related patents is much higher than the number that is shown in the analysis. 


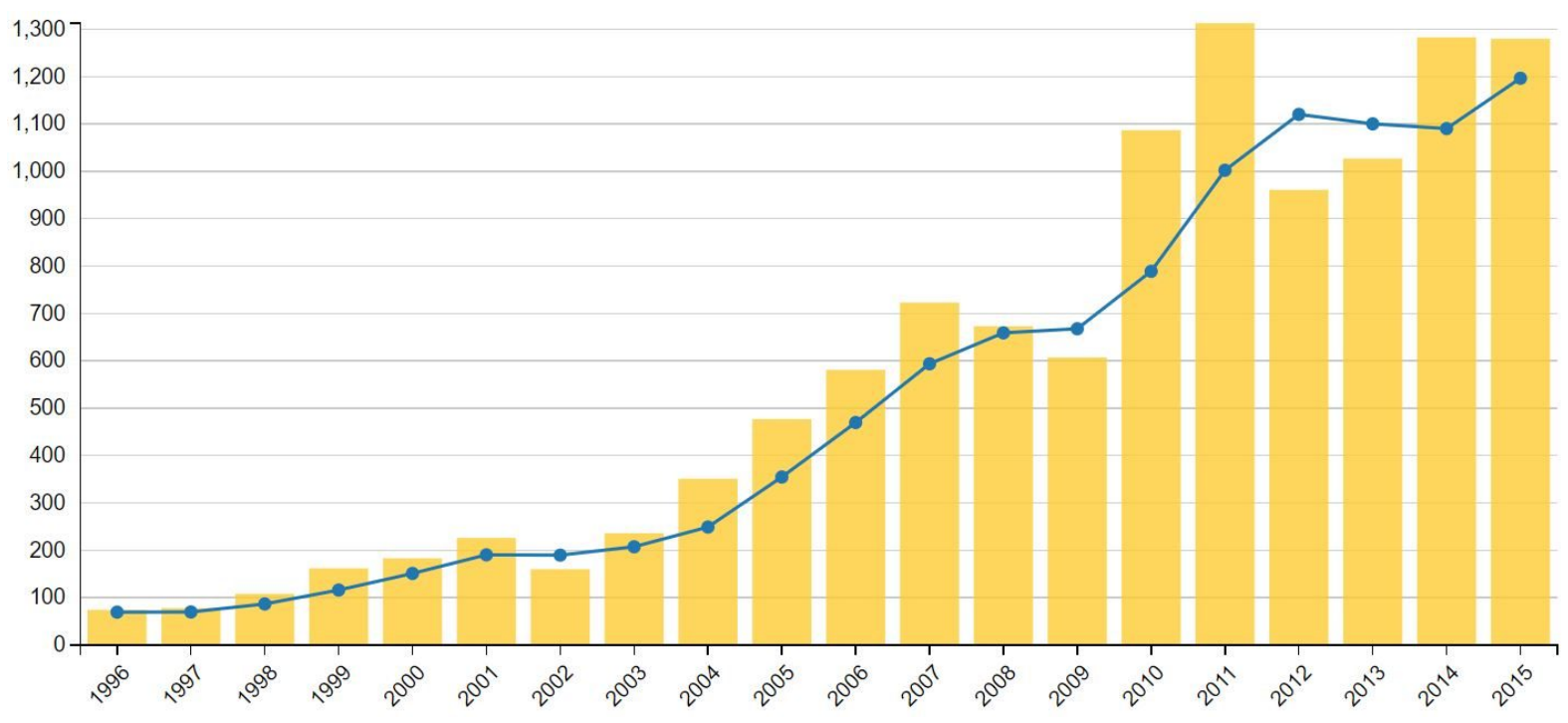

Figure 3. The number of granted patents over time illustrated via the program PatentInspiration. The search was done using the search terms 'biomim*', 'bionic*' and 'bio* inspired' (Filter=(biomim* OR bionic* OR "bio* inspired")) in the title, abstract and description. The bars indicate the number of granted patents, while the line indicates the trend.

\title{
2. BID PARADIGMS
}

Using inspiration from nature to develop new technology and products (biologically inspired design BID) can be approached using different paradigms namely problem-driven BID, solution-driven BID, biomimicry and bioreplication/biohacking. Each of those paradigms represent a distinct approach for how to address the problem to be solved, how to search and learn from nature and how to do the mimicry. A key issue is the level of abstraction applied in the mimicry and in the analysis and utilization of problems and biological phenomena. In the following we will describe each of those paradigms in more detail, give typical examples of their application and highlight how the paradigm has been used in various research projects.

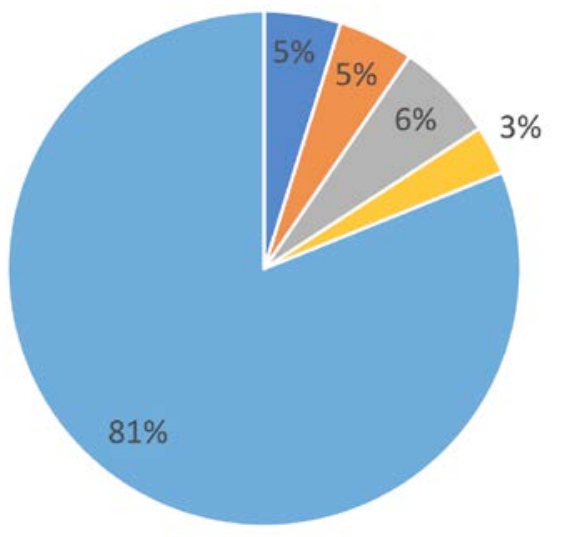

\author{
- Problem-driven BID \\ - Solution-driven BID \\ = Biomimicry \\ - Bioreplication \\ - Unknown
}

Figure 4. Amount of papers in Google Scholar for each of the BID paradigms. In total 346,000 papers were found for the search string (biomimicry OR biomimetics OR bionik OR bionic OR bio-inspired OR "biologically inspired design"). The other numbers were found by combining this search string with the following: Problem-driven: AND ("application driven” OR “problem driven” OR “top down” OR “design problem”) - 16,700 papers, solution-driven: AND ("inspiration driven" OR "bottom up" OR "design solution" OR "solution driven") - 16,500 papers, biomimicry: AND (sustainability OR closed-loop OR "circular economy" OR "cradle to cradle" OR "eco system") - 21,600 papers and bioreplication: AND (bioreplication OR bioimitation OR imitation OR “mirror systems") - 10,600 papers. 
Figure 4 gives an indication for how much work is done within each of the paradigms. Google scholar was searched using the search string biomimicry OR biomimetics OR bionik OR bionic OR bio-inspired OR "biologically inspired design" resulting in 346,000 publications. By combining the search string with synonyms for each paradigm the different percentages were found. Surprisingly, problem-driven BID scores relatively high. A possible explanation could be that practitioners within solution-based BID do not use the term 'solution-driven' or any of the synonyms and therefore fall into the large 'unknown' group.

\section{PROBLEM-DRIVEN BID}

In the problem-driven BID the starting point is the (engineering) problem for which suitable biological analogies are sought. The term problem-driven BID was coined by the cross disciplinary research group at Georgia Tech ${ }^{13}$ but the paradigm has been followed earlier by several research groups in Canada, Germany, Denmark and United Kingdom ${ }^{14-17}$. In Germany and Denmark the term top down biomimetics or top down bionik was used ${ }^{18}$ and in The Netherlands application-driven bio inspired design was preferred ${ }^{19}$. The paradigm can be regarded as a technology pull ${ }^{1,2}$ where the technology or product determines how to approach and search nature. The Asknature database of biological solutions also applies problem-driven BID in facilitating users with a search engine that can answer the question 'How would nature solve this problem? ${ }^{20}$.

\subsection{Design model}

Carrying out problem-driven BID requires that a design model is followed. The model specifies the sequence and content of the activities that lead the design team from a design problem to a design solution and could include the following activities: A. problem definition, B. problem framing, C. translation into biological search terms, D. search for biological analogies, E. selection and understanding of how the biological organism works, F. abstraction of key principles, G. design solutions, H. build prototypes and I. evaluate the quality of the developed solution.
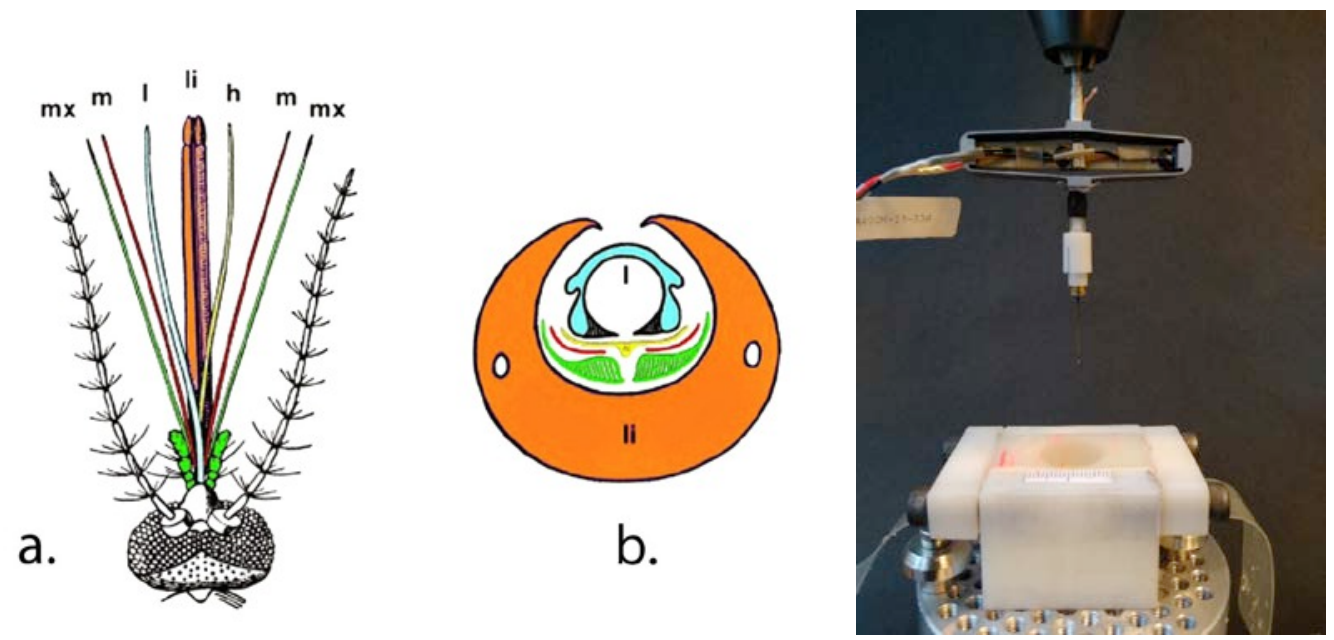

Figure 5. The mosquito proboscis (left): Seen from above (a) and cross section (b). li: labium, l: labrum, h: hypopharynx, m: mandible, mx: maxilla. Vibration unit (right) mimicking elements of the mosquito stinging mechanism ${ }^{21}$.

The use of a design model can be illustrated with an example which have previously been described in SPIE ${ }^{21}$ : How to make polymer needles. The problem definition (A) includes an analysis of the present use scenario and the improvement potentials. Today most medical needles for injections are made of metal to assure reliability and easy insertion. However, metal needles are considered dangerous waste after use, as it, unlike the rest of the syringe needs a dedicated waste stream. If the needles could be made of plastic, simpler waste handling would be possible for the combined syringe and needle. But plastic needles have much worse penetration properties than steel equivalents. The problem framing (B) is therefore how to ensure easy insertion of softer polymer needles. The biological search terms (C) could be 'skin penetration', 'biting' and 'stinging'. The search (D) finds insects like the stinging mosquito (Figure 5 left) and the protection mechanism in cnidarians (Jellyfish), where venomous pointed cells are shot into the threating animal. Understanding the biological analogy (E) can be done through literature study, collaboration with a biologist or a detailed study of the biological organism. For the mosquito, a range of supporting mechanisms like skin stretching, 
vibration (Figure 5 right), impulse and serrations together explains why the fairly flexible and very thin stinging proboscis can penetrate skin. Each of these mechanisms can then be abstracted and described as key principles (F). The principles are used to propose design solutions $(\mathrm{G})$ like a mechanical vibration mechanism that will lower the penetration force for a needle and hence reduce the requirements to its stiffness. This can be verified empirically with a prototype $(\mathrm{H})$ and an evaluation $(\mathrm{G})$ where the proposed solution is compared with similar solutions.

There exists a number of different design models covering all or some of the activities described above. The ISOstandard ${ }^{1}$ mentions a sequential model with 5 steps as shown in figure 6 . The focus is on the search and understanding of biological analogies and on the abstraction from the biological model. The initial phases where the problem is analysed and formulated is not treated in the standard. The Biomimicry Institute applies a design model they call the design spiral shown in figure $7 \mathrm{~A}^{22}$. It has 6 steps which cover all activities from the initial problem analysis (identify) to the final evaluation of the developed product. The shape of a spiral communicates that the model can be repeated in part or whole until a satisfactory result is achieved. Distinct contributions include the biomimicry taxonomy for problem framing, the Asknature database for search and life's principles for sustainability evaluation. The design model used by the Georgia Tech BID group also comprises 6 steps as shown in figure $7 \mathrm{~B}^{13}$. The steps in the model reminds of the steps in the design spiral. The major difference is the final evaluation step which is not directly mentioned in the Georgia Tech model. Distinct contributions are the 4 box and T-chart methods for problem analysis and comparison with biological analogy. The ParisTech group proposes a 9 step model shown in figure 8 which is inspired by the TRIZ methodology ${ }^{5}$. It covers the same activities as the design spiral, but subdivides some of the activities into separate actions. The DTU group uses a 5 step model shown in figure 9 which also covers all the steps from problem identification to final evaluation ${ }^{18,23}$. The distinct contribution for this model compared to the others is the focus on the so-called biocards which are used to communicate the abstracted functional biological principles. The single steps in the 5 design models are compared in table 1 which shows how the models correspond to each other.

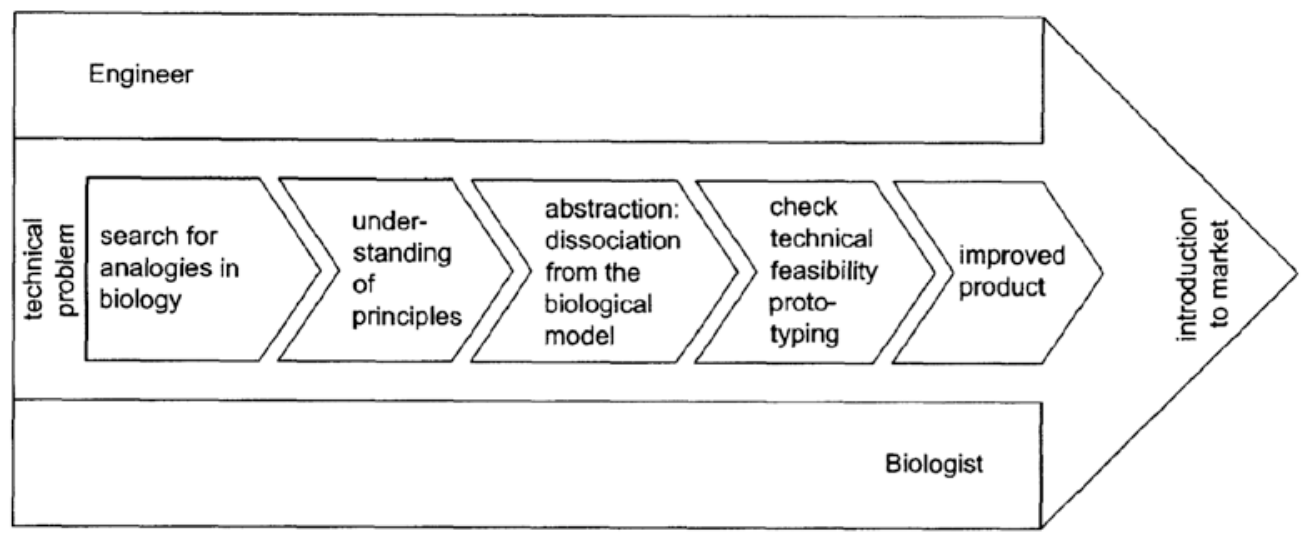

Figure 6. Typical technology pull BID development process as described by ISO ${ }^{1}$

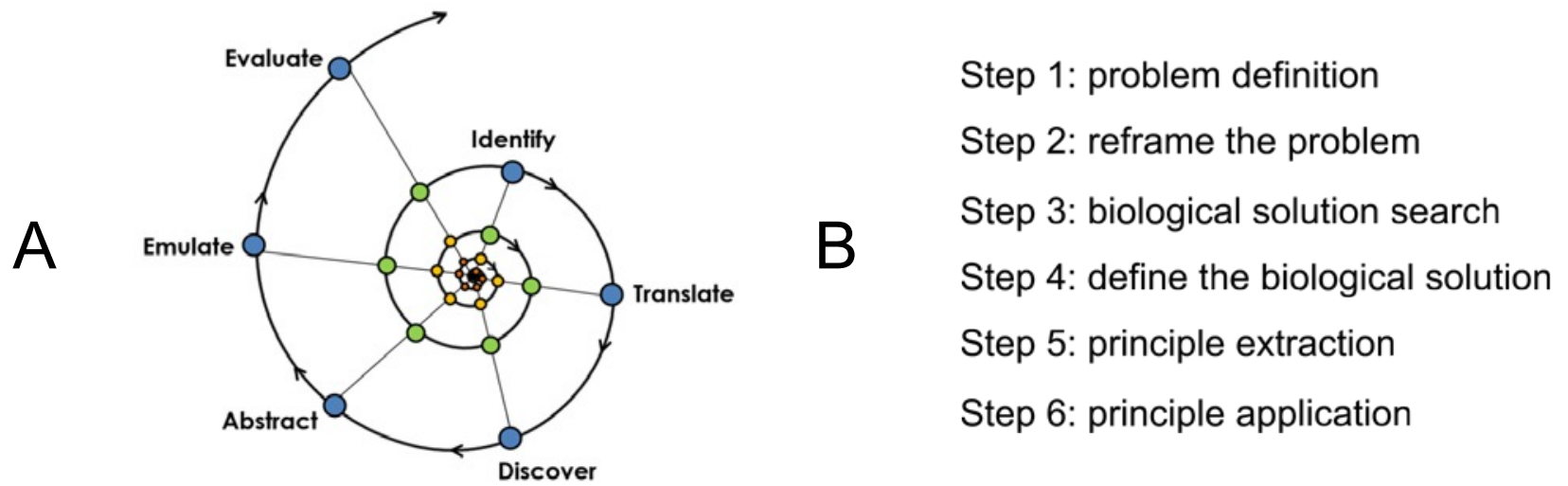

Figure 7. A: The 6 step design model called the design spiral used by the Biomimicry Institute ${ }^{22}$

B: The 6 steps in the Georgia Tech BID design model ${ }^{13}$ 


\begin{tabular}{|c|c|c|c|c|c|c|c|c|}
\hline 1. Identification & \multicolumn{2}{|c|}{ 2. Definition } & \multirow{2}{*}{$\begin{array}{l}\text { 3. Alternative } \\
\text { generation } \\
\text { 4. Identify } \\
\text { potential } \\
\text { biological } \\
\text { models }\end{array}$} & \multirow{2}{*}{$\begin{array}{l}\text { 4. Choice } \\
\text { of a } \\
\text { solution } \\
\begin{array}{c}5 . \text { Select } \\
\text { the }\end{array} \\
\text { biological } \\
\text { model of } \\
\text { interest }\end{array}$} & \multicolumn{4}{|c|}{ 5. Implementation and testing } \\
\hline $\begin{array}{l}\text { 1. Define the } \\
\text { human } \\
\text { needs/challenge }\end{array}$ & $\begin{array}{c}\text { 2. Abstract } \\
\text { the } \\
\text { technical } \\
\text { problem }\end{array}$ & $\begin{array}{l}\text { 3. Translate } \\
\text { into a } \\
\text { biological } \\
\text { challenge }\end{array}$ & & & $\begin{array}{l}\text { 6. Abstract } \\
\text { biological } \\
\text { strategie(s) }\end{array}$ & $\begin{array}{l}\text { 7. Translate } \\
\text { into a } \\
\text { technologica } \\
\text { 1 challenge }\end{array}$ & $\begin{array}{l}\text { 8. Implement } \\
\text { to the initial } \\
\text { situation }\end{array}$ & $\begin{array}{c}9 . \\
\text { Evaluate }\end{array}$ \\
\hline
\end{tabular}

Figure 8. The steps in the Paris Tech problem driven biomimetic process related to a general problem solving process 5

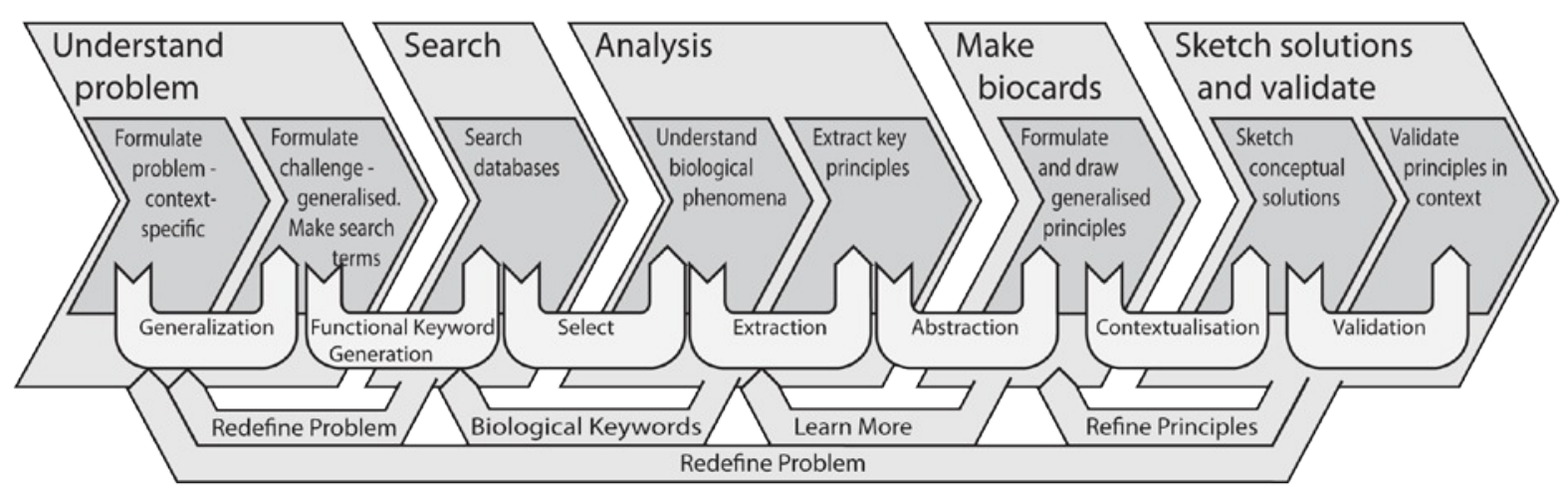

Figure 9. The 5 step design model from the DTU biocard method ${ }^{18,23}$

Table 1. Comparison of 5 design models for problem-driven BID. Light grey fields mark activities covered and darker grey fields are where the model has a distinct contribution.

\begin{tabular}{|c|c|c|c|c|c|c|c|c|c|}
\hline & $\begin{array}{c}\text { A } \\
\text { problem }\end{array}$ & $\begin{array}{c}\mathrm{B} \\
\text { frame }\end{array}$ & $\begin{array}{c}\mathrm{C} \\
\text { translate }\end{array}$ & $\begin{array}{c}\mathrm{D} \\
\text { search }\end{array}$ & $\begin{array}{c}\mathrm{E} \\
\text { select \& } \\
\text { understand }\end{array}$ & $\begin{array}{c}\mathrm{F} \\
\text { abstraction }\end{array}$ & $\begin{array}{c}\mathrm{G} \\
\text { design }\end{array}$ & $\begin{array}{c}\mathrm{H} \\
\text { build }\end{array}$ & $\begin{array}{c}\text { I } \\
\text { evaluate }\end{array}$ \\
\hline ISO model & $\begin{array}{c}0 \\
\text { Technical } \\
\text { problem }\end{array}$ & & & $\begin{array}{c}1 \\
\text { Search }\end{array}$ & $\begin{array}{c}2 . \\
\text { Understand } \\
\text { principles }\end{array}$ & $\begin{array}{c}3 . \\
\text { Abstraction } \\
\text { from } \\
\text { biological } \\
\text { model }\end{array}$ & & & $\begin{array}{c}4 \\
\text { Check } \\
\text { technical } \\
\text { feasibility }\end{array}$ \\
\hline $\begin{array}{l}\text { Biomimicry } \\
\text { design } \\
\text { spiral }\end{array}$ & \multicolumn{2}{|c|}{$\begin{array}{c}1 . \\
\text { Identify }\end{array}$} & $\begin{array}{c}2 . \\
\text { Translate, } \\
\text { biomimicry } \\
\text { taxonomy } \\
\end{array}$ & $\begin{array}{c}3 . \\
\text { Discover, } \\
\text { Asknature }\end{array}$ & & $\begin{array}{c}4 . \\
\text { Abstract }\end{array}$ & \multicolumn{2}{|c|}{$\begin{array}{c}5 . \\
\text { Emulate }\end{array}$} & $\begin{array}{c}6 . \\
\text { Evaluate, } \\
\text { Life's } \\
\text { principles }\end{array}$ \\
\hline $\begin{array}{l}\text { Georgia } \\
\text { tech model }\end{array}$ & $\begin{array}{c}1 . \\
\text { Problem } \\
\text { definition, } \\
\text { 4box } \\
\end{array}$ & \multicolumn{2}{|c|}{$\begin{array}{c}2 . \\
\text { Reframe the problem, } \\
\text { T-chart }\end{array}$} & $\begin{array}{c}3 . \\
\text { Search }\end{array}$ & $\begin{array}{c}4 \\
\text { Define the } \\
\text { biological } \\
\text { solution } \\
\end{array}$ & $\begin{array}{c}5 . \\
\text { Principle } \\
\text { extraction }\end{array}$ & \multicolumn{2}{|c|}{$\begin{array}{c}6 . \\
\text { Principle application }\end{array}$} & \\
\hline $\begin{array}{l}\text { Paris Tech } \\
\text { model }\end{array}$ & $\begin{array}{c}1 . \\
\text { Define } \\
\text { need }\end{array}$ & $\begin{array}{c}2 . \\
\text { Abstract } \\
\text { technical } \\
\text { problem }\end{array}$ & $\begin{array}{c}3 . \\
\text { Translate } \\
\text { into } \\
\text { biological } \\
\text { challenge }\end{array}$ & $\begin{array}{c}4 . \\
\text { Identify } \\
\text { biological } \\
\text { models }\end{array}$ & $\begin{array}{c}5 . \\
\text { Select } \\
\text { biological } \\
\text { model }\end{array}$ & $\begin{array}{c}6 . \\
\text { Abstract } \\
\text { biological } \\
\text { strategy }\end{array}$ & $\begin{array}{c}. \\
\text { Translate } \\
\text { into } \\
\text { technical } \\
\text { challenge }\end{array}$ & $\begin{array}{c}8 . \\
\text { Implement }\end{array}$ & $\begin{array}{c}9 . \\
\text { Evaluate }\end{array}$ \\
\hline $\begin{array}{l}\text { DTU } \\
\text { biocard } \\
\text { model }\end{array}$ & \multicolumn{2}{|c|}{$\begin{array}{c}\text { 1a. } \\
\text { Formulate problem }\end{array}$} & $\begin{array}{c}\text { 1b. } \\
\text { Generalize } \\
\text { into biol. } \\
\text { terms }\end{array}$ & $\begin{array}{c}2 . \\
\text { Search }\end{array}$ & $\begin{array}{c}3 . \\
\text { Understand } \\
\text { and focus }\end{array}$ & $\begin{array}{c}4 . \\
\text { Abstract } \\
\text { principles, } \\
\text { biocards }\end{array}$ & \multicolumn{2}{|c|}{$\begin{array}{c}5 \mathrm{a} . \\
\text { Sketch }\end{array}$} & $\begin{array}{c}5 \mathrm{~b} . \\
\text { Validate }\end{array}$ \\
\hline
\end{tabular}




\subsection{BioTRIZ}

For designers to successfully use biologically inspired design in a systematic way with the problem driven approach, we need efficient methods to translate biological abstractions into technical solutions. One promising way is to expand the Russian Theory of Inventive Problem Solving (TRIZ) to include biological solutions ${ }^{24}$. TRIZ is a method for developing innovative solutions based on a large 39x39 matrix of contradicting features (for example wanting something larger, but also lighter). Each field in the matrix has a number of possible solutions (for example use of gasses or generation of lift) developed from hundreds of thousands of patents.

Julian Vincent and co-workers adapted and simplified this method into a 6 x 6 matrix (using the fields: substance, structure, space, time, energy and information) and populated it with both traditional engineering solutions condensed from the larger TRIZ matrix and with biological solutions analysed from about 2500 conflicts and their resolutions ${ }^{25}$. While initially seen as a promising approach with some notable successes such as allowing a comparison between problem solving in engineering (TRIZ) and biology (BioTRIZ) showing only a $12 \%$ overlap $^{24}$, BioTRIZ has failed to gain widespread recognition or usage ${ }^{25}$. However, the underlying assumption that TRIZ has significant potential for biomimetics remains and current efforts aim at utilising more of the original TRIZ tools than just the contradiction matrix including abstraction and transferring tools ${ }^{26,27}$ and the development of a BioOntology that move away from the simple dialectic approach in the contradiction matrix and a one-to-one database to include the overlap of several inventive principles to better capture the complexity and dynamic nature of biological systems ${ }^{25}$.

\section{SOLUTION-DRIVEN BID}

In the section above, we heard how designers can systematically search for biologically inspired answers to clearly defined engineering problems via the problem-driven or top-down approach. However, most biomimetics studies have so far been conducted by the alternative solution-driven or bottom-up approach. This method is less systematic and typically occurs as a result of serendipitous discoveries of fascinating biological processes or mechanisms.

Solution-driven BID takes the fascination of interesting and remarkable biological phenomena as a starting point and subsequently analyses these to identify key principles and then search for suitable applications. The paradigm has been phrased solution-driven BID $^{13}$, bottom up biomimetics ${ }^{18}$, inspiration-driven biologically inspired design ${ }^{19}$ and biology push $^{1,2}$.

The most famous biomimetic example - that of Velcro - followed this pattern as the Swiss engineer George de Mestrel allegedly got the inspiration for inventing Velcro in the 1940s, when he was out walking with his dog and noticed how the seed chambers of the burdock plant - the cockleburs - attached themselves to the fur of his $\operatorname{dog}^{6}$. Upon his return, he started to investigate the 100 s of small hooks on the cockleburs, which after a lot of trial and error let him to patent the unique two-way fasteners consisting of one side of tiny hooks inspired by the cockleburs and one side of soft loops inspired by the dog's fur.

As mentioned, this process is usually not carried out in a clear systematic manner, but Helms et al. ${ }^{13}$, nonetheless developed a framework for solution-driven BID consisting of the following 7 steps:

Step 1: Biological Solution Identification - This is where the biological process or mechanism is encountered or discovered (for example cockleburs forming strong attachments to dog fur).

Step 2: Define the biological solution - Here the mechanisms are described and explained (tiny hooks make the cockleburs attach to the fur).

Step 3: Principle Extraction - The core principle is extracted from the biological process or mechanisms (multiple stiff hooks adhere to multiple looped hairs).

Step 4: Reframing the Solution - How might the biological mechanism or process be redesigned to be applied to human technology (multiple mini hooks can form strong attachment to multiple mini loops). 
Step 5: Problem Search - Exploration of which problems in our technology this principle can be the solution to. This may sometimes involve developing novel problems - i.e. new applications or novel technology (the hooks and loops principle can dynamically be used to attach and detach).

Step 6: Problem Definition - Narrowing down the problems identified in step 5 to extract a clearly defined problem or application (the hook and loop dynamic fastener principle could be used in fabrics that need to attach and detach rapidly such as shoes, jackets etc.).

Step 7: Principle Application - Apply the developed principle to prototypes and final products (apply the Velcro hooks and loops to clothes and compare to traditional methods).

In most examples, where the solution-driven BID approach has been used (usually without this being explicitly acknowledged), steps 1-3 and sometimes 4 and 5 have been carried out by biologists, who are experts on the given organisms and by accident or due to scientific curiosity discover the novel mechanisms.

In the following, we give examples of how this approach has been utilised (again without implying that the scientists were doing this in a systematic way or consciously using the steps outlined above) in five of the most famous biomimetics examples and include some of the challenges encountered in successfully translating the biological solutions.

\subsection{The cleaning effect of Lotus leaves}

The Lotus effect is the mechanism by which small epicuticular wax crystals on the leaf surface of some plants, including the sacred lotus plant, allow the plants to self-clean by giving water a stronger adhesion to dirt particles than to the leaf surface $^{28}$. The mechanism was discovered accidentally when botanists, who were investigating the surfaces of leaves from a large number of species, observed that smooth leaves were much dirtier than rough leaves (step 1). From these initial observations, the exact nature of the roughness and its hydrophobic effect was quantified and the principles of their function extracted under the name of the Lotus effect (step 2 and 3). These steps were all completed by the botanists, lead by Willem Barthlott, who discovered the mechanism and they further suggested possibly applications in self-cleaning surfaces and paint (step 4 and 5) ${ }^{28}$. Barthlott patented the Lotus effect in 1995 and the company Sto SE \& Co acquired the patent and started producing the paint Lotusan (step 6 and 7), which is now commercially available and has demonstrated advantages including being more cost effective compared to traditionally paints ${ }^{29}$. Thus, the Lotus effect is a clear example of a successful application of solution-driven BID.

\subsection{The adhesion of gecko feet}

Scientists and laypeople alike have long been marvelling at the extraordinary ability of geckos to adhere to, and climb on, vertical surfaces (step 1). However, the mechanism behind this achievement was first explained at the beginning of this century by biologists demonstrating that the thousands of hairs on each gecko foot each has more than 100s of minute spatula-shaped structures and that these adhere to surfaces via Van der Waals forces ${ }^{30,31}$ (step 2). Within a few years, the Nobel prize winning physicists Andre Geim and colleagues had extracted the principles and produced a prototype 'gecko tape' made by microfabrication of dense arrays of flexible plastic pillars ${ }^{32}$ (steps 3, 4 and 5). However, challenges with durability and staying clean (dust accumulates which reduces adhesion - the gecko overcomes this by regularly cleaning its feet with its tongue) has meant that gecko tape is still not commercially available (step 7 not achieved). A further potential issue with gecko tape is the problem definition (step 6). While the main applications have focussed on static and semi-permanent adhesion (i.e. as a tape), the gecko uses the adhesion dynamically in a sequence of rapid attachments and detachments ${ }^{33}$.

\subsection{The material properties of spider silk}

It has long been recognised that spider silk is a remarkable biomaterial allowing, among other things, spiders to catch fast flying and large prey with an ultralight weight web. It is particularly the frame threads (also used in the safety threads that spiders trail behind them when moving) that due to their combination of high strength and high elasticity has an exceptionally high toughness, which is necessary in order to absorb the high kinetic energy of the prey (step 1) ${ }^{34,35}$. The biochemical structure of the silk is also fairly well understood and it is the composite nature of the silk consisting of amorphous flexible chains and stiff polyalanine arranged into hydrogen-bonded beta-pleated sheets (step 2 and partly $3)^{36}$. However, the process of spinning occurring inside the spider, where the silk changes from a liquid phase in the glands and ducts to the solid phase extruded by the spinnerets via a complicated mechanical and chemical process is still not fully understood (step 3 not fully completed) ${ }^{37}$. Thus, while biomimetic applications including in protective clothes 
and crash helmets have been identified (step 4 and 5), and the biochemical structure is known and the liquid silk proteins can be produced by genetically modified bacteria, the biomimetic spinning process has not yet been mastered and artificial silk is therefore currently much inferior to natural silk ${ }^{33}$. However, while commercial products relying on spider silks' unique material properties are a long way off (step 6 and 7 not achieved), the biocompatibility and organic breakdown of artificial or reconstituted silk makes it potentially very useful as suture threads in surgery and for other biomedical applications ${ }^{38}$.

\subsection{The defensive mechanisms of the bombardier beetle}

The bombardier beetles (a subgroup of the ground beetles) display a fascinating and highly efficient defensive behaviour. They squirt hot noxious chemicals at would-be predators in a rapid and directed fashion (step 1). The exact biochemical method whereby this liquid is produced was already explained by biologists in the late $1960 \mathrm{~s}^{39}$. The liquid is produced when two separately stored chemicals (hydroquinone and hydrogen peroxide) are joined together in a chamber inside the beetle, where catalysts facilitate the decomposition of the hydrogen peroxide and the oxidation of the hydroquinone. This heats up the liquid close to the boiling point, which results in high pressure and an explosive reaction (step 2 and 3). Half a century later, engineers extracted the main principles by developing a numerical computational fluid dynamics model and using it to build a scaled up prototype of the combustion chamber with the aim of using the technique to improve gas turbines and produce pressure relief valve systems that can deliver a periodic pulsed spray (step 4 and 5$)^{40}$. The company Swedish Biomimetics 3000 is attempting to utilise this technology in $\mu$ MIST ${ }^{\circledR}$ to develop the ability to spray highly viscous formulations, without requiring flammable and environmentally damaging propellants (step 6$)^{41}$. However, to date no commercially available products have been developed (step 7 not fully achieved).

\subsection{The fog collection by the Namib desert beetle}

The Namib desert beetles are capable of extracting liquid water in the form of droplets from morning fog in the otherwise dry desert (step 1). The method with which this is achieved was explained by biologist Andrew Parker and engineer Chris Lawrence ${ }^{42}$. They found that the surface of the elytra (or wing casings) in these beetles is bumpy with a mixture of smooth hydrophilic non-waxy regions and textured hydrophobic waxy regions. Water droplets from surrounding fog forms on the hydrophobic peaks and rapidly grows in size until they roll down the elytra and into the beetle's mouth as they adopt a curious headstand posture - also known as fog-basking behaviour. The elytra surface and posture can potentially be easily imitated by inclined textured artificial surfaces (step 2, 3 and 4). However, a later study found that several other beetle species with only smooth hydrophobic elytra were in fact more efficient fog collectors questioning the necessity for the textured surface for fog harvesting to work ${ }^{43}$. Parker and Lawrence identified potential applications in the form of water-trapping tent and building covering or portable water-extractors (step 5). A prototype has recently been produced by depositing superhydrophobic nano-particles in a mesh placed on a hydrophilic copper sheet $^{44}$. The prototype was shown to be an efficient method of fog collection with excellent anti-corrosion ability (step 6 and 7).

\subsection{Status of solution-driven BID}

Thus, in conclusion, solution-driven BID has generated a large number of novel biomimetic applications, but as illustrated with the examples selected above, few have as of yet resulted in commercial successful products (only Velcro and Lotusan can be classified as successes). The main challenges are due to insufficient understanding of the biological mechanisms (spider silk), misapplying the process (dynamic attachment and reattachment in geckos used as inspiration for static attachment in tape) and/or problems with simplifying and replicating the process (spider silk and defensive mechanism in bombardier beetles). It is also worth noting that in all of the examples highlighted here, the first 3-4 steps (and for the Lotus effect, the first 6 steps) were completed by biologists before engineers and physical scientists took over illustrating the need for including both biologists and engineers in the solution-driven BID process.

\section{BIOMIMICRY}

The term 'biomimicry' scopes the technical transformation of biological forms, processes, patterns, and systems into $\operatorname{artefacts}^{45,46}$. The connection of biomimicry to sustainability is inherent, as the evolutionary process of nature creates resource efficient results which should support the solution of ecological challenges caused by mankind ${ }^{47,48}$. Cohen and Reich $^{49}$ generated an overview of terminology of different biomimetic design directions. They argue that the sustainability driven BID as a paradigm cannot be separated from the paradigms described above. It occurs as problem- 
driven as well as solution driven approaches. The difference is the explicit focus on sustainability, especially the environmental sustainability. Therefore, this section will not only consider the term biomimicry, but also look at bioinspiration, biomimetics and bionics, if their application supports at least one of the criteria of sustainability.

\subsection{Sustainability}

Traditionally sustainability is described including three dimensions: the economic, the social and the environmental dimensions $s^{2,50,51}$. United Nations has recently further concretized these dimensions into 17 sustainability goals ${ }^{52}$. The focus of sustainability driven BID is in many cases the environmental dimension, but especially the evaluation of the results from a sustainability driven BID-process is not meaningful without the economic dimension. In the following we will mainly be considering the environmental dimension of sustainability.

It is often assumed, that a BID product or system is automatically sustainable but that is not always the case. Speck and colleagues gives an example where a light weight product inspired by nature might save economic and environmental resources in building it, but the geometric shape might be so complex, that the production cost exceeds the saved material saving costs ${ }^{2}$. Another example is poisonous animals and plants, which are the result of a natural production process but never the less are harmful to humans and other natural beings. The poisonous organisms serve their purpose within their ecological niche but the poisonous element cannot be taken out of context claiming sustainability. Speck et al. further describe how the descriptive, normative and emotional aspect of bio-derived developments are taken into consideration when looking at sustainability. The descriptive aspect aims at facilitating knowledge transfer between similar BID applications and proposes a classification into 17 classes for this purpose. The normative aspect aims at evaluating to what extend a proposed solution is sustainable while the emotional aspect deals with the comprehension of the product and the biological analogy. The Biomimicry Institute propose to use the Life's Principles to evaluate the sustainability of a product - see the evaluation section later in the paper.

For the evaluation of environmental sustainability quantitative methods for life cycle assessment (LCA) are widely used. Examples are 'pro Suite', 'PROSA', 'Calcas' as described by Speck and colleagues ${ }^{2}$. The LCA-tools calculate the impact of a product on the environment and translates it into indicators such as CO2-equivalents. The LCA-result is not an absolute measurement of sustainability but gives a relative number that can be used to compare new solutions to existing ones. To that end is normally defined a functional unit for comparison, for example the transport of one person a given distance in order to compare different transport solutions.

\subsection{Biomimicry levels}

The Biomimicry Institute defines 3 levels of biomimicry having increased complexity ${ }^{46,45}$. The first level of biomimicry concerns the mimicking of natural forms such as the imitation of frayed owl wing edges to achieve silent flight. The second level scopes the transfer of natural processes into technical solutions for example the way green chemistry is inspired by self-assembly of owl feathers at room temperature. The third level has the highest requirement as it covers the mimicking of natural ecosystems, also named as deep, holistic or eco biomimicry. It implicates the integration of all elements and the relationship between the elements in a more or less closed ecosystem. An example is the consideration of the owl feather as part of a forest and a sustaining biosphere. To achieve sustainable solutions level 3 biomimicry should be aimed for. Solutions found at the 2 lower levels need not being sustainable ${ }^{46,53}$.

An engineering counterpart to the biomimicry levels is classification into a number of levels with increasing complexity ${ }^{54,55}$. One is the distinction between the organism level, the behavior level, and the systems level, an approach, which stems from mechanical engineering design ${ }^{56,49}$. We have used five levels to classify 5 examples of biomimicry: The system level on the top followed by products, components / modules, parts / elements and materials. Figure 10 place the example at the different levels and show their relation to the biomimicry levels. The technical examples seem to indicate the following tendency: Using natural forms are mainly to be found on the technical site at the element and component level. Natural processes (as second level) are implemented from the material up to products and devices, whereas mimicking ecosystems are mostly applied to the systems and product level.

In megacities, there is increasing demand for climate regulation and purification of the air. This has increased the interst in natural mechanisms for air filtration and the increased plantation of trees and the concept of an urban green infrastructure ${ }^{57}$. In extension to the contribution of parks and tree lined alleys, there is an increasing relevance of designing and implementing items of urban greenery to green roofs and facades ${ }^{62}$. However, as urban trees grow significantly faster than their rural conspecifics, they manifest a more rapid ageing and thus shortened lifetime which induces the need for new concepts integrating plants into megacities to ensure their contribution to the urban 
ecosystem ${ }^{57}$. The example illustrate that it is not enough to mimic (or in this case copy) the natural organism but the ecological system in wood has to be considered.

\begin{tabular}{|c|c|c|c|c|}
\hline $\begin{array}{c}\text { Hierarchy of } \\
\text { technical artefacts }\end{array}$ & Application & Mimicking & Authors & Biomimicry levels \\
\hline Systems & $\begin{array}{l}\text { Purification of air } \\
\text { in megacities }\end{array}$ & $\begin{array}{c}\text { CO2 uptake } \\
\text { and renewal } \\
\text { of plants }\end{array}$ & Pretzsch $^{57}$ & $\begin{array}{c}3 \\
\text { Eco- }\end{array}$ \\
\hline Products, devices & $\begin{array}{l}\text { Ventilation in } \\
\text { buildings }\end{array}$ & $\begin{array}{l}\text { African } \\
\text { termite } \\
\text { mound }\end{array}$ & Pearce $^{58}$ & \\
\hline $\begin{array}{l}\text { Components, } \\
\text { modules }\end{array}$ & $\begin{array}{c}\text { Blades of fans and } \\
\text { turbines, facades }\end{array}$ & $\begin{array}{l}\text { Bumps on } \\
\text { humpback } \\
\text { whale fins }\end{array}$ & $\begin{array}{l}\text { Z. Čarija } \\
\text { et al. }\end{array}$ & \\
\hline Elements, parts & $\begin{array}{l}\text { Infrared sensor } \\
\text { for fire-detection } \\
\text { in buildings }\end{array}$ & $\begin{array}{l}\text { Pyrophilous } \\
\text { beetle }\end{array}$ & $\begin{array}{l}\text { Klocke, et } \\
\text { al. }^{60}\end{array}$ & $\begin{array}{c}2 \\
\text { Natural } \\
\text { Processes }\end{array}$ \\
\hline Material & Impact protection & Spider silk & Scheibel $^{61}$ & \\
\hline
\end{tabular}

Figure 10: 5 examples of biomimicry classified using the Biomimicry levels and a traditional engineering hierarchy of technical systems.

One of the most well-known examples for buildings in tropical zones is the passive ventilation system at the Eastgate Building, Harare, Zimbabwe - which mimics the African termite mound ventilation system by the Architect Mick Pearce $^{58}$. The ventilation system reduces the energy consumption. It represents a smaller element in the building complex and illustrates that a termite mound being a more isolated system which utilize natural processes can be mimicked with positive sustainability consequences.

The efficiency of mechanical ventilation fans and energy producing windmills have been improved with inspiration from the bumps on humpback whale fins. The bumps reduces the drag and reduces the risk of stalling ${ }^{59}$. The bumps are an example of how a natural form inspires to an improved component design.

Fire detection is traditionally done using energy consuming sensors that register either infrared radiation or smoke particles. Pyrophilous (fire-loving) insects utilize a mechanical sensor that detect very small volume fluctuations caused by infrared radiation ${ }^{60}$. This can be mimicked to for passive, i.e. not consuming energy, sensors and hence be more sustainable. It is an example of a single element which inspires on the natural process level.

As earlier described does spider silk represent a unique combination of strength and elasticity ${ }^{61,34,35}$. This makes it possible to produce more light weight impact resistant structures and thus save energy when transported. Even though the basic spider silk chemistry can be mimicked the unique properties require a better understanding of the spinning process, i.e. it is at the natural process biomimicry level.

\section{BIOREPLICATION}

Bioreplication can be considered a special type of solution-based BID where the biological structure is directly reproduced with the purpose of realizing at least one specific functionality. The basic steps are the same as described for solution-driven design but the nature of the work done within each step is different. The term is often used within nanotechnology research where a range of very accurate production techniques make it possible to replicate geometry at a nano-level ${ }^{4,63,64}$. These techniques include the sol-gel technique, atomic layer deposition, physical layer deposition, imprint lithography combined with casting and the use of focused ion beams for removing or depositing material at a 
very small areas ${ }^{4}$. The techniques are in particular used for optical devices since micro and nano-scale features can be made.

The replication of the iridescent elytra of the Ash borer beetle is a fine example of bioreplication ${ }^{65,66}$. The Ash Borer is an invasive species and means for limiting their numbers were sought. The purpose of the replica was to produce a decoy that would lure male Ash Borer beetles to mate with the decoy and then kill them with electrical shocks. The underlying hypothesis was that the sexual attraction mechanism for the beetle was a visual signal produced by the nanostructure on the female beetle elytra. Instead of analyzing the detailed photonic structure of the elytra a casting process was used to make a replica of the original elytra. The replica demonstrated that the attraction mechanisms could be replicated and attract male beetles. This illustrates how bioreplication is a valuable technique since delicate nano-structures can be reproduced with relatively simple means and used to explore the functionality of biological structures.

An example of bioreplication on a macro scale is the early development of drag reducing bended wing tips on aircrafts. The bended wing tips are seen in many larger birds and can explain the reduced need for energy for propulsion ${ }^{67}$. Having realized the causal relationship between wingtips and reduced drag a solution-driven BID approach could be to build wing models where the geometry and proportion of the wing tip could be changed. It this way the details of the drag reduction mechanism could be understood and biomimetic design rules could be formulated. In contrast to this a bioreplication approach could be to directly replicate the bird wing, e.g. by taking casts of wings fixated in the right position, which would be much faster. On the other hand, the bio-replication would most likely not reveal details about the relationship between the design parameters and the resulting effect.

The development in technology makes it easier for many (untrained) people to manipulate biology, e.g. with synthetic biology, and create radically new technologies ${ }^{68}$. The do-it-yourself biology movement is sometimes also referred to as bio-hacking, with reference to decentralized computer movement. Due to the widespread use of open-source knowledge sharing in these communities the movement has an innovative potential. Bioreplication is a very feasible approach for this purpose.

\section{TASKS IN BID}

All of the four BID paradigms utilize to a larger or smaller degree a number of generic BID tasks, like problem clarification, abstraction of technical and biological functions, search for biological analogies or applications, validation of biological abstractions, and evaluation of product solutions. Table 2 describe how the different generic tasks relate to the steps in each paradigm. In the following we will describe the tools that support these tasks and highlight their importance and relevance.

Table 2. Generic tasks and their relation to steps in each paradigm

\begin{tabular}{|l|c|c|c|c|}
\hline Generic BID Tasks & $\begin{array}{c}\text { Problem-driven } \\
\text { BID }\end{array}$ & $\begin{array}{c}\text { Solution-driven } \\
\text { BID }\end{array}$ & Biomimicry & Bioreplication \\
\hline Problem clarification & Step A+B & Step 6 & $\begin{array}{c}\text { Biomimicry } \\
\text { taxonomy }\end{array}$ & Step 6 \\
\hline Abstraction & Step C + F & Step 3 & & Asknature \\
\hline Search & Step D & Step 5 & (Step 5) \\
\hline Understand & Step E & Step 2 + & & Step 2) + 4 \\
\hline $\begin{array}{l}\text { Validation of } \\
\text { biological abstraction }\end{array}$ & Step G & Step 3 & & Step 7 \\
\hline Evaluation of solution & Step H+I & Step 7 & Life's principles & \\
\hline
\end{tabular}

\subsection{Problem clarification}

In any design process a crucial step is the clarification of the problem to be solved. If you do not ask the right questions the answers might be worthless. For the problem-driven paradigm this is the first initial activity where the engineering problem is analysed and the central challenging elements identified. For the solution-driven paradigm the clarification 
comes in at a much later stage in the development namely after the biological phenomena has been understood and mimicked and a suitable application is needed. For the solution-driven case the problem clarification is similar to the situation when new materials or technologies have been developed and a search for applications are initiated.

For problem-driven BID the clarification is often done by making a so-called design brief where background and context are described and characteristics of the desired solutions described. Since the design brief is intended to stimulate a creative generation of new ideas it is important that possible solutions are not mentioned in the brief since they would limit and constrain the possible solution space. The brief is normally a textual description but it can be complemented with a visual description where the nature of the problem is described, e.g. as a sequence of drawings describing the existing and desired future situation. A simple example could be the problem of dirty windows where a solution to cleaning is desired. A drawing of a dirty and a clean window would highlight the goal of the development work, but not describe the means to do the cleaning. Drawing for problem clarification in an integral part of the DTU biocard method $^{23}$. A major advantage of the visual representation is the communicative value for the development team and other stakeholders, where the focus can be kept on the core problem rather than on the details of the proposed solution.

Another tool is the 4-box analysis method proposed and used by the Georgia Tech BID-group ${ }^{69}$. The 4-box analysis include a description of 4 elements: The operational environment, the functions, the specifications and performance criteria. Apart from enforcing a broader description of the problem the 4-box can be used in a multifaceted comparison of the problem and the proposed biological analogies using the so-called T-chart tool ${ }^{69}$.

The Biomimicry Institute has developed a functional classification they call the Biomimetic taxonomy ${ }^{70}$. The classification has 3 levels each with a number of categories. In total, there are 8 categories at the lowest level, 30 at the next level and 158 at the third. The use of the taxonomy can be illustrated with an example using the design of a cleaning mechanism for dry sanitation for developing countries ${ }^{71}$. The 3 level categories are 'protect from physical harm', 'protect from non-living threats' and 'dirt/solids'. This classification can be used to search nature and for instance find how newly hatched small birds wrap the fecal matter as small parcels which the adult birds remove from the nest and in that way, protect it against predators. The bio-inspired solution was a wrapping mechanism that made encapsulation of fecal matter possible and hence removed the need for cleaning. The intention behind the biomimicry classification is to allow users to ask the question 'how would nature solve this problem' and make search easier. All the records in the Asknature database have been classified using the taxonomy making an effective search possible. However, the taxonomy is also very useful for searches in other databases or in literature.

\subsection{Abstraction}

For the first 3 BID paradigms, a key element is abstraction where central principles are identified and described. For problem-driven BID the abstraction takes place after the problem has been identified and described and the search for biological analogies is prepared. The problem is often described in context specific (technical) terms which will yield poor results if used for searching biological texts. For example, the technical problem in driving on icy surfaces can be formulated as 'insufficient friction' but a search on friction in biological text would not find all relevant biological analogies such as animal claws, slug slime or the gecko setae. An abstraction is therefore needed from the concrete technical formulation into more abstract terms (or even to more biology oriented terms).

In their natural search approach for BID, Shu and colleagues propose a set of techniques for abstraction and identification of relevant search terms to be used for the biological search ${ }^{3}$. They strongly recommend to use verbs instead of nouns since the nouns are much more likely to find pre-conceived analogies. Verbs on the other hand will describe actions and hence be better at finding a greater variety of biological forms. As an example, they describe how the verb 'protect' will find a greater variety of phenomena than if the noun 'cuticle' was used. They also describe how certain verbs can be considered as biologically meaningful (significant or connotative) and if they occur within certain frequencies they can be considered as bridge words which are more likely to be helpful in the biological search.

Ahmed-Kristensen et al. gives further argument to why it is important to make abstractions ${ }^{72,73}$. Using search terms well known to the person that searches causes a significant risk of design fixation - only solutions that are similar to what the person already knows about is found. They argue that truly novel ideas, i.e. ideas of concepts unknown to the person, are much more likely to occur when far analogies are used. Far analogies are much easier to find when searching nature compared to searching existing technical solutions provided that the search terms are not too closely related to concepts already known by the person. 


\subsection{Search}

The search task has mainly been explored and developed for problem-driven BID but is also relevant for solution-driven BID where the challenge is to find relevant applications once the principles for an interesting biological phenomenon is understood. In the first case search is used to explore which biological phenomena that can solve a given problem. The search is typically done in literature available in public and commercial databases. Challenges in performing the search include minimizing search time and ensure that there are surprising and unknown search results. There are two generic types of search for BID:

- the natural language search ${ }^{14,74-77}$ in general or dedicated databases,

- the search based on pre-defined categories and keywords in special designed and prepared databases.

To use natural language search, it is an advantage if the user has insight into biology and engineering. The important limitation of the natural language search are the different terminologies of engineers and biologists. The natural language search is less difficult if the field of interest within engineering and biology is narrow making it easier to learn the special terms and their translation. However, a narrow search also limits the amount of possible alternative solutions meaning that the search engineer is less likely to come up with radically new ideas. The use of structured tools as part of BIDtailored databases is a possible solution to this problem. BID-tailored databases with pre-defined categories and keywords have as prerequisite a mapping of attributes and functions of biological and technical systems. But as there is no consistent standardized and theoretical founded model of mapping engineering and biological matters, the available BID- databases differ widely.

BID-databases can be characterized by the level of concreteness. The more concrete content that is provided the more extensive the database and the user-interface. They also differ by the coverage of concrete biological solutions for engineering problems, and by the model for mapping biological and engineering items. Here we find

- adaptions of classical design supporting tools like TRIZ, transformed into BioTRIZ, but still using most of the classical structure and categories ${ }^{78}$,

- creations of independent models, more or less theoretical substantiated, like the approaches of Hill, Löffler and Gramann, as analysed by Helms ${ }^{79}$

- models which connect at least partly to a consistent and standardized meta-model, but with relevant differences on the concrete level, like the approach from Wilson, and tools like IDEA-INSPIRE, DANE (Design by Analogy to Nature Engine), Biologue ${ }^{74}$, and the AskNature- database ${ }^{20}$.

Vandemme and colleagues studied the impact of using databases to BID. The study was based on the AskNature database, and a control-group not using the tool and the overall conclusion was "The results consistently support a common claim used in favour of bio-inspired design, i.e. the expectation of identifying more out-of-the-box solutions." ${ }^{, 80}$. However, there are serious limitations for use of BID-databases. With the permanent increase in research results from biology, it seems an overwhelming assignment to keep updating the databases within an acceptable effort and time. This leads to the conception and application of tools for an automated classification "to integrate the large amounts of existing biological strategies much faster than currently is the case" ${ }^{\prime \prime 0}$. To overcome the obstacle of natural search and search by classification a range of methods are being developed including the method of using 'association lists', 'bridging verbs' and 'BioScrabble, ${ }^{79}$. Associative acting tools like the BioScrabble have been tested successfully with engineering master students, but despite positive results the application of tools like BioScrabble are not widespread since it mainly has been reported in German literature.

\subsection{Understand}

An important step in applying biological principles for designing products is the understanding of how the biological phenomena actually work. In many cases the functionality can be straight forward to understand for mechanically oriented engineers for example the biomechanics in walking, jumping, flying and swimming ${ }^{81}$. But in general, it is easier for people with biological training to read and understand biological texts explaining the biological functional mechanisms. In particular, the more complicated causal relationships in biochemistry can be hard to grasp for the mechanically oriented engineers, even though the principles underlying the phenomena can be valuable for generating solution ideas. 
The role of collaboration between engineers and biologist has been studied in Munich ${ }^{82}$. Different teams of either engineers, biologists or mixed teams were given short BID assignments. Even though the results were not statistically significant, there was a tendency towards better performance in the mixed teams. The cross disciplinary collaboration is an advantage not only for each discipline having access to extended competences but also for supporting the differences in terminology between the 2 fields. However, there are large differences in mind-set, values and working procedures between engineers and biologists which should be overcome for the collaboration to be successful.

The generic task of understanding is solved differently within the paradigms. Since much of the work on solution-driven BID is initiated and driven by biologists, understanding is typically a minor problem. Contrary for problem-driven BID which most often is initiated by engineers the task of understanding how the biological phenomena works can be a major challenge which limits the range of ideas that is explored.

\subsection{Validation}

To validate if proposed biological abstractions actually can be used to solve the initial problems physical or computer models normally needs to be produced. The models determine to what extend the functionality observed in nature can be simplified and mimicked. An example is the mechanism that prevent individuals in flocks colliding, e.g. in birds murmuration and in fish schools. The basic mechanism was explained by a movie animator who formulated 3 simple rules and showed that a computer program where the rules were implemented could simulate the flock behavior ${ }^{83}$.

The validation can work as a motivating factor for cross disciplinary collaboration, and can to some extent explain the increased interest in biomimetics. The reason is the development within nano-technology and synthetic biology, where biologist find collaborators that can help them make good models and the engineers see opportunities to demonstrate how their expertise can be expanded to other areas. This can be seen within bio-photonics where physicists with insight into advanced computer modelling and thin layer manufacturing techniques makes it possible to understand and describe the advanced structural colour phenomena found in nature such as the bright blue colours in morpho butterflies and the antireflection in moth eyes ${ }^{84}$.

\subsection{Evaluation}

Once a new product is developed using bio-inspiration it can be evaluated whether it solves the problem better than existing solutions. The immediate evaluation within a BID development project can be done based on the developed models looking at how well they satisfy the initial requirements. However, this evaluation only determines if the found solution is realistic but not whether it represents something new. To that end a set of metrics is being used to evaluate not only if the solution is (more) useful but also if it is novel. Shah ${ }^{85}$ describes four metrics: Novelty, variety, quality and quantity. The degree of novelty is determined by searching for similar solutions. Quality tells us if the solution actually solves the problem in a satisfactory way. Quantity and variety tells how many alternative solutions have been proposed and how different they are. This is a measurement of the size of the explored solution space and serves as an indication of how likely it is that the optimal solution has been found. Another tool for evaluating the developed solution is the Indian SAPPhIRE model for causality ${ }^{86,87}$. This model evaluates at which level of abstraction the proposed solution is different from existing solutions. The evaluation metrics can be used in problem-driven BID to judge the quality of the proposed solution and in solution-driven BID to assess if the biological principles for a given phenomenon have potential for further development.

The Biomimicry Institute uses the so-called 'life's principles' in the Biomimicry DesignLens to evaluate the degree of sustainability a proposed solution represents ${ }^{88}$. The principles can be used to measure proposed designs against natures sustainable benchmarks. There are 6 principles:

- $\quad$ Evolve to survive

- Adapt to changing conditions

- Be locally attuned and responsive

- Use life-friendly chemistry

- Be resource efficient

- Integrate development with growth 
The principles are used in the evaluation process but not necessarily as an exact quantitative measurement. It is of course possible for some of the principles to compare exact values for the performance of a proposed design against existing solutions. But the main value lies in the evaluation process when looking on the performance with respect to each of the principles which can be more qualitative in nature, e.g. that recycling is possible and realistic.

\section{CONCLUSION}

There is a growing interest into the topic of biologically inspired design. This has been documented in earlier studies where an exponential growth in number of published papers and patents was found. We have updated these studies and found that the number of publications and patents are still increasing, even though not exponentially as previously observed. Within the last years the growth has evened out with a tendency of slower growth in the most recent years. This could suggest that the growth rate now follow a sigmoid pattern.

Biologically inspired design (BID) can be approached following at least 4 different paradigms: problem-driven BID, solution-driven BID, biomimicry and bioreplication. There are similarities in the single steps followed when carrying out the BID work between the different paradigms but also major differences. The paper has described the paradigms and what characterizes them and given examples of their application. It also describes the generic BID tasks which are used across the paradigms but in different orders. The tasks include the problem clarification, the abstraction of technical and biological functions, the search for biological analogies or applications, the validation of biological abstractions, and the evaluation of product solutions.

Biologically inspired design is still a very young discipline and the coming research is just about to take form. A good question is what are the next steps in biomimetics research. One tendency is the increased multi-disciplinary work where biologist, engineers and computer scientists collaborate to develop and fine tune the methods and tools applied in each paradigm. Another tendency is the information technology based developments which will make it possible to bridge knowledge between different domains and therefore allow for a better knowledge transfer between biology and engineering thanks to intelligent search algorithms. A third direction concerns the basic motivation that attract research interest into the area. Presently the motivation for working with BID can roughly be described as 'nature is an enormous source of unknown knowledge', 'surprising biological phenomena can revolutionize technical products', 'nature is sustainable', and 'biology can show the way to utilize new technology' each corresponding to the 4 BID paradigms. Maybe the future will show that these motivations are closer related than it first seems.

\section{REFERENCES}

[1] ISO 18458., "Biomimetics-Terminology, Concepts and Methodology,” ISO 2015 (2015).

[2] Speck, O., Speck, D., Horn, R., Gantner, J.., Sedlbauer, K. P., "Biomimetic bio-inspired biomorph sustainable? An attempt to classify and clarify biology-derived technical developments," Bioinspiration and Biomimetics 12(11004) (2017).

[3] Shu, L. H., Ueda, K., Chiu, I.., Cheong, H., "Biologically inspired design,” CIRP Ann. - Manuf. Technol. 60(2), 673-693 (2011).

[4] Pulsifer, D. P.., Lakhtakia, A., "Background and survey of bioreplication techniques," Bioinspiration and Biomimetics 6(3) (2011).

[5] Fayemi, P. E., Maranzana, N., Aoussat, A.., Bersano, G., "Bio-inspired design characterisation and its links with problem solving tools,” Proc. Int. Des. Conf. Des. 2014-Janua, D. Marjanović, M. Štorga, N. Pavković, and N. Bojčetić, Eds., 173-182, The Design Society, Glasgow, UK. (2014).

[6] Hesselberg, T., "Biomimetics and the case of the remarkable ragworms," Naturwissenschaften 94(8), 613-621 (2007).

[7] Snell-Rood, E., "Interdisciplinarity: Bring biologists into biomimetics," Nature (2016).

[8] Lepora, N. F., Verschure, P.., Prescott, T. J., "The state of the art in biomimetics," Bioinspiration and Biomimetics 8(1) (2013).

[9] Bonser, R. H. C., "Patented Biologically-inspired Technological Innovations: A Twenty Year View," J. Bionic Eng. 3(1), 39-41 (2006).

[10] Bonser, R. H. C.., Vincent, J. F. V., “Technology trajectories, innovation, and the growth of biomimetics,” Proc. 
search engine, $2017,<($ http://ec.espa-cenet.com) $>$.

[13] Helms, M., Vattam, S. S.., Goel, A. K., "Biologically inspired design: process and products," Des. Stud. 30(5), 606-622 (2009).

[14] Shu, L. H., Lenau, T. A., Hansen, H. N.., Alting, L., "Biomimetics applied to centering in microassembly," CIRP Ann. 52(1), 101-104 (2003).

[15] Gramann, J., "Problemmodelle und Bionik als Methode," Technischen Universität München (2004).

[16] Lindemann, U.., Gramann, J., “Engineering design using biological principles,” Des. 2004 Int. Des. Conf. 44(0), 1-6, The Design Society, Dubrovnik (2004).

[17] Stricker, H. M., "Bionik in der Produktentwicklung unter der Berücksichtigung menschlichen Verhaltens," Technischen Universität München (2006).

[18] Lenau, T., Dentel, A., Invarsdottir, T.., Gudlaugsson, T., "Engineering design of an adaptive leg prosthesis using biological principles," 11th Int. Des. Conf. (design 2010), 331-340 (2010).

[19] Adrichem, M., "CoBID a co-evolutionary bio inspired method," Delft University of Technology (2011).

[20] The Biomimicry Institute., "AskNature - Innovation Inspired by Nature," < https://asknature.org/> (23 January 2018 ).

[21] Lenau, T. A., Hesselberg, T., Drakidis, A., Silva, P.., Gomes, S., "Mosquito inspired medical needles," SPIE Conf. Bioinspiration, Biomimetics, Bioreplication 2017, M. Knez, A. Lakhtakia, and R. J. Martín-Palma, Eds., SPIE - International Society for Optical Engineering, Portland, Oregon, USA (2017).

[22] DeLuca, D., "The power of the Biomimicry Design Spiral," Biomimicry Inst., 2017, $<$ https://biomimicry.org/biomimicry-design-spiral/>.

[23] Lenau, T. A., "Do biomimetic students think outside the box?," Proc. 21st Int. Conf. Eng. Des. 4(21), 543-551, Vancouver, Canada, 21.-25.08.2017 (2017).

[24] Vincent, J. F. V., Bogatyreva, O. A., Bogatyrev, N. R., Bowyer, A.., Pahl, A.-K., "Biomimetics: its practice and theory," J. R. Soc. Interface 3(9), 471-482 (2006).

[25] Vincent, J., "TRIZ as a Primary Tool for Biomimetics," [Research and Practice on the Theory of Inventive Problem Solving (TRIZ)], L. Chechurin, Ed., Springer, Cham, 243-256 (2016).

[26] Schöfer, M., Maranza, N., Aoussat, A.., Bersano, G., "Testing the Value of Triz and Its Derivatives for Knowledge Transfer in Problem Solving Attempts By Multidisciplinary Teams,” ICED13 19th Int. Conf. Eng. Des.(August), 1-10 (2013).

[27] Fayemi, P.-E., Maranzana, N., Aoussat, A.., Bersano, G., "Assessment of the Biomimetic Toolset—Design Spiral Methodology Analysis,” Smart Innov. Syst. Technol. 35(January), A. Chakrabarti, Ed., ICoRD'15 Research into Design Across Boundaries Volume 2: Creativity, Sustainability, DfX, Enabling Technologies, Management and Applications (2015).

[28] Neinhuis, C.., Barthlott, W., "Characterization and distribution of water-repellent, self- cleaning plant surfaces," Ann. Bot. 79(6), 667-677 (1997).

[29] Antony, F., Griesshammer, R., Speck, T.., Speck, O., "The cleaner, the greener? Product sustainability assessment of the biomimetic facade paint Lotusan $(\mathrm{R})$ in comparison to the conventional facade paint Jumbosil (R),” Beilstein J. Nanotechnol. 7, 2100-2115 (2016).

[30] Autumn, K., Liang, Y. A., Hsieh, S. T., Zesch, W., Chan, W. P., Kenny, T. W., Fearing, R.., Full, R. J., “Adhesive force of a single gecko foot-hair," Nature 405(6787), 681-685 (2000).

[31] Autumn, K., Sitti, M., Liang, Y. A., Peattie, A. M., Hansen, W. R., Sponberg, S., Kenny, T. W., Fearing, R., Israelachvili, J. N., et al., "Evidence for van der Waals adhesion in gecko setae.," Proc. Natl. Acad. Sci. U. S. A. 99(19), 12252-12256, National Academy of Sciences (2002).

[32] Geim, A. K., Dubonos, S. V., Grigorieva, I. V., Novoselov, K. S., Zhukov, A. A.., Shapoval, S. Y., "Microfabricated adhesive mimicking gecko foot-hair," Nat. Mater. 2(7), 461-463 (2003).

[33] Wolff, J. O., Wells, D., Reid, C. R.., Blamires, S. J., "Clarity of objectives and working principles enhances the success of biomimetic programs," Bioinspiration and Biomimetics 12(5), IOP Publishing (2017).

[34] Denny, M. W., "the Physical Properties of Spider'S Silk and Their Role in the Design of Orb-Webs," J. Exp. Biol. 65, 483-506 (1976).

[35] Gosline, J. M., DeMont, M. E.., Denny, M. W., "The structure and properties of spider silk," Endeavour 10(1), 37-43 (1986).

[36] O’Brien, J. P., Fahnestock, S. R., Termonia, Y.., Gardner, K. H., "Nylons from nature: Synthetic analogs to 
spider silk," Adv. Mater. 10(15), 1185-1195 (1998)

[37] Vollrath, F.., Knight, D. P., "Structure and function of the silk production pathway in the spider Nephila edulis," Int. J. Biol. Macromol. 24(2-3), 243-249 (1999).

[38] Hakimi, O., Knight, D. P., Vollrath, F.., Vadgama, P., "Spider and mulberry silkworm silks as compatible biomaterials,” Compos. Part B Eng. 38(3), 324-337 (2007).

[39] Aneshansley, D. J., Eisner, T., Widom, J. M.., Widom, B., "Biochemistry at $100^{\circ} \mathrm{C}$ : Explosive Secretory Discharge of Bombardier Beetles (Brachinus)," Science (80-. ). 165(3888), 61-63 (1969).

[40] Beheshti, N.., Mcintosh, A. C., "The bombardier beetle and its use of a pressure relief valve system to deliver a periodic pulsed spray," Bioinspiration and Biomimetics 2(4), 57-64 (2007).

[41] " " $\mu$ mist Platform Technology.", Swedish Biomimetics 3000 AB, 2018, $<\mathrm{http}: / /$ swedishbiomimetics.com/technologies/\%CE\%BCmist/>.

[42] Parker, A. R.., Lawrence, C. R., "Water capture by a desert beetle," Nature 414(6859), 33-34 (2001).

[43] Nørgaard, T.., Dacke, M., "Fog-basking behaviour and water collection efficiency in Namib Desert Darkling beetles," Front. Zool. 7, 1-8 (2010).

[44] Yin, K., Du, H., Dong, X., Wang, C., Duan, J.., He, J., "A simple way to achieve bioinspired hybrid wettability surface with micro/nanopatterns for efficient fog collection," Nanoscale, 14620-14626, Royal Society of Chemistry (2017).

[45] Benyus, J., Biomimicry - Innovation inspired by nature, HarperCollins Publishers Inc, New York, NY, United States (2009).

[46] Benyus, J. M., “A Biomimicry Primer - A Biomimicry Primer” (2017).

[47] Wanieck, K., Fayemi, P.-E., Maranzana, N., Zollfrank, C.., Jacobs, S., "Biomimetics and its tools," Bioinspired, Biomim. Nanobiomaterials 6(2), 53-66 (2017).

[48] Kennedy, E. B.., Marting, T. A., "Biomimicry: Streamlining the front end of innovation for environmentally sustainable products," Res. Technol. Manag. 59(4), 40-48 (2016).

[49] Cohen, Y. H.., Reich, Y., Biomimetic Design Method for Innovation and Sustainability, Springer (2016).

[50] Brundtland, G., "Report of the World Commision on Environement and Development: Our Common Future," Oxford Pap. Report of, 400 (1987).

[51] United Nations General Assembly., "2005 World Summit Outcome” (2005).

[52] "Sustainable development goals - United Nations.", <http://www.un.org/sustainabledevelopment/sustainabledevelopment-goals/> (7 February 2018 ).

[53] Volstad, N. L.., Boks, C., "Biomimicry - a useful tool for the industrial designer? Shedding light on nature as a source of inspiration in industrial design," Nord. 2008, 10 (2008).

[54] Simon, H. A., "The Architecture of Complexity," Proc. Am. Philophical Soc. 106(6), 467-482 (1962).

[55] Murmann, J. P.., Frenken, K., "Toward a systematic framework for research on dominant designs, technological innovations, and industrial change," Res. Policy 35(7), 925-952 (2006).

[56] Gero, J. S.., Kannengiesser, U., “A function-behavior-structure ontology of processes,” Artif. Intell. Eng. Des. Anal. Manuf. AIEDAM 21(4), 379-391 (2007).

[57] Pretzsch, H., Biber, P., Uhl, E., Dahlhausen, J., Schütze, G., Perkins, D., Rötzer, T., Caldentey, J., Koike, T., et al., "Climate change accelerates growth of urban trees in metropolises worldwide /631/158/858 /704/158/2165 article," Sci. Rep. 7(1), 1-10 (2017).

[58] Pearce, M., "Eastgate Shopping Centre Ventilation," 2018, <http://www.mickpearce.com/Eastgate.html>.

[59] Čarija, Z., Marušić, E., Novak, Z.., Fućak, S., "Numerical Analysis of Aerodynamic Characteristics of a Bumped Leading Edge Turbine Blade,” Eng. Rev. 34(2), 93-101 (2014).

[60] Klocke, D., Schmitz, A., Soltner, H., Bousack, H.., Schmitz, H., "Infrared receptors in pyrophilous ('fire loving') insects as model for new un-cooled infrared sensors," Beilstein J. Nanotechnol. 2(1), 186-197 (2011).

[61] Scheibel, T., "Spinnenseide - was Spiderman wissen sollte," BIOspektrum 15, 1-3 (2010).

[62] Wootton-Beard, P., Xing, Y., Durai Prabhakaran, R., Robson, P., Bosch, M., Thornton, J., Ormondroyd, G., Jones, P.., Donnison, I., "Review: Improving the Impact of Plant Science on Urban Planning and Design," Buildings 6(4), 48 (2016).

[63] Lakhtakia, A.., Martín-Palma, R. J., Engineered Biomimicry, Eng. Biomimicry, A. Lakhtakia and R. J. MartínPalma, Eds., Elsevier (2013).

[64] Risbud, A. S.., Bartl, M. H., "Solution-Based Techniques for Biomimetics and Bioreplication," [Engineered Biomimicry] (2013).

[65] Pulsifer, D. P., Lakhtakia, A., Narkede, M. S., Domingue, M. J., Post, B. G., Kumar, J., Martín-Palma, R. J.., 
Baker, T. C., "Fabrication and testing of artificial emerald ash borer visual decoys," Proc. SPIE 8686(April 2013), 1-4 (2013).

[66] Domingue, M. J., Pulsifer, D. P., Narkhede, M. S., Engel, L. G., Martín-Palma, R. J., Kumar, J., Baker, T. C.., Lakhtakia, A., "Fine-scale features on bioreplicated decoys of the emerald ash borer provide necessary visual verisimilitude," Proc. SPIE - Int. Soc. Opt. Eng. 9055(March 2014), 905507 (2014).

[67] Tucker, V., "Gliding birds: reduction of induced drag by wing tip slots between the primary feathers," J. Exp. Biol. 180(1), 285-310 (1993).

[68] “Do-it-yourself biology.”, Wikipedia, 2017, <https://en.wikipedia.org/wiki/Do-it-yourself_biology>.

[69] Helms, M.., Goel, A. K., "The Four-Box Method: Problem Formulation and Analogy Evaluation in Biologically Inspired Design,” J. Mech. Des. (2014).

[70] "Biomimicry Taxonomy.", The Biomimicry Insitute, 2017, <https://asknature.org/resource/biomimicrytaxonomy/\#.Wncvhku1v_Q>.

[71] Lenau, T.., Hesselberg, T., "Dry sanitation concepts with inspiration from nature," J. Water Sanit. Hyg. Dev. 5(2) (2015).

[72] Ahmed, S.., Christensen, B. T., "An In Situ Study of Analogical Reasoning in Novice and Experienced Design Engineers," J. Mech. Des. 131, 111004-1 (2009).

[73] Ahmed-Kristensen, S., Christensen, B. T.,, Lenau, T., "Naturally Original: Stimulating Creative Design Through Biological Analogies and Random Images," Proc. ASME 2013 Int. Des. Eng. Tech. Conf., Portland,Oregon (2013).

[74] Goel, A. K.., Shu, L. H., “Analogical thinking: An introduction in the context of design,” Artif. Intell. Eng. Des. Anal. Manuf. AIEDAM 29(2), 133-134 (2015).

[75] Cheong, H.., Shu, L. H., "Using templates and mapping strategies to support analogical transfer in biomimetic design,” Des. Stud. 34(6), 706-728 (2013).

[76] Chiu, I.., Shu, L. H., "Biomimetic design through natural language analysis to facilitate cross-domain information retrieval," Artif. Intell. Eng. Des. Anal. Manuf. 21, 45-59 (2007).

[77] Chiu, I.., Shu, L. H., "Using language as related stimuli for concept generation," Artif. Intell. Eng. Des. Anal. Manuf. 21, 103-121 (2007).

[78] Verhaegen, P. A., Peeters, J., Vandevenne, D., Dewulf, S.., Duflou, J. R., "Effectiveness of the PAnDA ideation tool," Procedia Eng. 9, 63-76, Elsevier B.V. (2011).

[79] Helms, M. K., "Biologische Publikationen als Ideengeber für das Lösen technischer Probleme in der Bionik," Dissertation Technical University München (2016).

[80] Vandevenne, D., Pieters, T.., Duflou, J. R., "Enhancing novelty with knowledge-based support for BiologicallyInspired Design,” Des. Stud. 46, 152-173 (2016).

[81] Vogel, S., Comparative biomechanics : life's physical world, Princeton University Press (2003).

[82] Hashemi Farzaneh, H., "Bio-inspired design: Ideation in collaboration between mechanical engineers and biologists," Technische Universität München (2016).

[83] Reynolds, C. W., "Flocks, herds and schools: A distributed behavioral model," ACM SIGGRAPH Comput. Graph. 21(4), 25-34 (1987).

[84] Vukusic, P.., Sambles, J. R., "Photonic structures in biology," Nature 424(August), 852-855 (2003).

[85] Shah, J. J.., Vargas-Hernandez, N., "Metrics for measuring ideation effectiveness," Des. Stud. 24, 111-134 (2003).

[86] Keshwani, S., Lenau, T. A., Ahmed-Kristensen, S.., Chakrabarti, A., "Comparing novelty of designs from biological-inspiration with those from brainstorming," J. Eng. Des. 28(10-12), 654-680 (2017).

[87] Chakrabarti, A., Sarkar, P., Leelavathamma, B.., Nataraju, B. S., "A functional representation for aiding biomimetic and artificial inspiration of new ideas," Artif. Intell. Eng. Des. Anal. Manuf. AIEDAM 19(2), 113132 (2006).

[88] Biomimicry 3.8., "Biomimicry DesignLens - Life's Principles," The Biomimicry Insitute, 1-17 (2015). 